\title{
Gabapentin as an adjuvant for postoperative pain management in dogs undergoing mastectomy
}

\author{
Giulianne Carla CROCIOLLI ${ }^{1)}$, Renata Navarro CASSU ${ }^{1) *}$, Rafael Cabral BARBERO ${ }^{1)}$, Thalita Leone A ROCHA ${ }^{1)}$, \\ Denis Robson GOMES ${ }^{1)}$ and Gabriel Montoro NICÁCIO ${ }^{1)}$ \\ ${ }^{1)}$ Department of Veterinary Surgery and Anesthesiology, Faculty of Veterinary Medicine, Universidade do Oeste Paulista, Presidente \\ Prudente, Brazil
}

(Received 18 November 2014/Accepted 16 March 2015/Published online in J-STAGE 29 March 2015)

\begin{abstract}
This study aimed to evaluate the analgesic efficacy of gabapentin as an adjuvant for postoperative pain management in dogs. Twenty dogs undergoing mastectomy were randomized to receive perioperative oral placebo or gabapentin $(10 \mathrm{mg} / \mathrm{kg})$. All dogs were premedicated with intramuscular acepromazine $(0.03 \mathrm{mg} / \mathrm{kg})$ and morphine $(0.3 \mathrm{mg} / \mathrm{kg})$. Anesthesia was induced with propofol $(4 \mathrm{mg} / \mathrm{kg})$ intravenously and maintained with isoflurane. Intravenous meloxicam $(0.2 \mathrm{mg} / \mathrm{kg})$ was administered preoperatively. Postoperative analgesia was evaluated for $72 \mathrm{hr}$. Rescue analgesia was provided with intramuscular morphine $(0.5 \mathrm{mg} / \mathrm{kg})$. Dogs in the Placebo group received significantly more morphine doses than the Gabapentin group $(P=0.021)$, despite no significant differences in pain scores. Perioperative gabapentin reduced the postoperative morphine requirements in dogs after mastectomy.
\end{abstract} KEY WORDS: canine, gabapentin, morphine, multimodal analgesia

doi: 10.1292/jvms.14-0602; J. Vet. Med. Sci. 77(8): 1011-1015, 2015

Mammary tumors are the most common neoplasias in dogs and are commonly treated by an extensive mastectomy which results in inflammation, edema and moderate to severe postoperative pain [21]. Postoperative pain is not purely nociceptive in nature and may consist of inflammatory, neurogenic and visceral components [17]. Therefore, multimodal analgesic techniques utilizing a number of drugs which act on different analgesic mechanisms are becoming increasingly popular [5, 14, 19, 23].

Gabapentin is a non-opioid medication, structurally ana$\log$ of gamma-amino butyric acid, which has been used as an anticonvulsant and antinociceptive drug [9]. In humans, several studies have shown that perioperative gabapentin helps to produce a significant opioid-sparing effect and decreases the postoperative pain score compared with placebo groups $[3,4,6]$. In veterinary medicine, two previous reports showed relevant analgesic effects using gabapentin as an adjuvant for the treatment of hyperalgesia and allodynia in dogs and cats $[2,24]$. In contrast, in dogs undergoing amputation of a forelimb, perioperative gabapentin did not provide a significant benefit for postoperative pain management [26]. The aim of this study was to evaluate the analgesic efficacy of gabapentin as an adjuvant for postoperative pain management in dogs.

This study was performed following the guidelines of

*Correspondence to: Cassu, R. N., Department of Veterinary Surgery and Anesthesiology, Faculty of Veterinary Medicine and Animal Science, Unoeste, 19067-175, Presidente Prudente, Brazil. e-mail: renavarro@uol.com.br, navarro@unoeste.br

(C2015 The Japanese Society of Veterinary Science

This is an open-access article distributed under the terms of the Creative Commons Attribution Non-Commercial No Derivatives (by-nc-nd) License $<$ http://creativecommons.org/licenses/by-nc-nd/3.0/>. the Brazilian College of Animal Experimentation, and the experimental procedure was approved by an institutional animal care committee (protocol 1182-CEEA). Informed consent was obtained from the owners of all the dogs. Twenty female dogs, aged 6 to 12 years (median, 9.2 years) and weighing between 2.7 and $29.3 \mathrm{~kg}$ (median, $10.6 \mathrm{~kg}$ ), undergoing elective mastectomy of at least 4 mammary glands were enrolled. The preoperative condition of each dog was evaluated through a physical examination and laboratory tests (i.e., complete blood cell count, measurements of the urea, creatinine, alanine aminotransferase and aspartate aminotransferase levels). All the dogs met the following inclusion criteria: American Society of Anesthesiologists physical status of III or less, no arterial hypertension or congestive heart failure, no renal or hepatic dysfunction and no pulmonary metastases. The dogs were randomly assigned to one of the two groups, with 10 animals in each. The dogs were orally (PO) administered with either $10 \mathrm{mg} / \mathrm{kg}$ (1 $\mathrm{m} l / 5 \mathrm{~kg}$ ) of gabapentin solution (Neurotin Oral solution, 50 $\mathrm{mg} / 5 \mathrm{ml}$, Pfizer, New York, NY, U.S.A.) (Gabapentin, $\mathrm{n}=10$ ) or $1 \mathrm{ml} / 5 \mathrm{~kg}$ of placebo solution (Placebo, $\mathrm{n}=10$ ) $120 \mathrm{~min}$ prior to surgery. The placebo was produced with the inactive ingredients of the gabapentin oral solution (glycerin, xylitol, purified water and artificial cool strawberry anise flavor.) The postoperative gabapentin or placebo was continued for three days after surgery beginning $12 \mathrm{hr}$ after the preoperative dose. A random number generator (Research Randomizer, Computer software, http://www.randomizer.org/) was used to assign 10 dogs to each of the two groups.

After withdrawing food and water for $12 \mathrm{hr}$ and $3 \mathrm{hr}$, respectively, all dogs were premedicated with $0.03 \mathrm{mg} / \mathrm{kg}$ acepromazine (Acepran 0.2\%, Univet São Paulo, Brazil) in combination with $0.3 \mathrm{mg} / \mathrm{kg}$ morphine (Dimorf, Cristália, Brazil) intramuscularly (IM). Twenty min after the premedi- 
cation, an intravenous catheter (Insyte, Becton Dickinson, São Paulo, Brazil) was aseptically placed in a cephalic vein, and anesthesia was induced with $4 \mathrm{mg} / \mathrm{kg}$ propofol (Propovan, Cristália, Brazil). Orotracheal intubation was performed, and anesthesia was maintained with isoflurane in $100 \%$ oxygen using a small animal rebreathing circuit (Samurai, Takaoka, São Paulo, Brazil). Surgical procedures were performed by the same experienced surgeon, using the same surgical technique. The extent of mastectomy was defined as a percentage of mammary tissue excised, an entire mammary gland chain corresponding to a $100 \%$ mastectomy [19]. Lactated Ringer's solution (5 to $10 \mathrm{~m} / / \mathrm{kg} / \mathrm{hr}$ ) was administered throughout the procedure. All dogs received an initial dose of $0.2 \mathrm{mg} / \mathrm{kg}$ meloxicam (Movatec, Roche, São Paulo, Brazil), intravenously, 5 min prior to surgery and additional daily doses of meloxicam $(0.1 \mathrm{mg} / \mathrm{kg}, \mathrm{PO})$, beginning $24 \mathrm{hr}$ after extubation and continuing for up to 10 days.

Based on the anesthetic record, surgery time (time elapsed from the first incision until placement of last suture), extubation time (time elapsed from termination of isoflurane until extubation) and recovery time (time elapsed from the end of anesthesia until standing positon) were recorded for each dog. Extubation was performed when the dog started coughing and/or gagging from the endotracheal tube.

The administration of postoperative analgesic drugs was supervised by one anesthesiologist, and the pain assessment was performed by a blinded assessor. The pain level was measured prior to the premedication (baseline scores) and at $0.5,1,2,4,8,12,18,24,32,40,48,56,64$ and $72 \mathrm{hr}$ after extubation using the modified Glasgow Composite Measure Pain Scale (GCMPS, 0-10) [15, 23]. In addition, pain was assessed using a Visual Analogue Scale (VAS, 0-100 mm) in which, $0=$ no pain and $100=$ worst possible pain, manifested by vocalization, aggression and refusal to allow the examination $[18,19,23]$. Dogs judged to have moderate to severe pain (VAS $\geq 50 \mathrm{~mm}$ or GCMPS $\geq 3.3$ ) were given morphine $(0.5 \mathrm{mg} / \mathrm{kg}, \mathrm{IM})$ [23]. At each pain assessment, sedation was scored according to a scale that ranged from 0 to 4, as follows: normal behavior (0); mild sedation, some decrease in normal activity, some resistance to handling, responds to name (1); moderate sedation, easy to handle, still spontaneously active, responds to name, but more slowly (2); moderate to heavy sedation, less spontaneous activity, verbal encouragement needed to rise, minimal resistance to handling (3); sternal recumbency, physical stimulus required to rise, depressed, no resistance to handling (4) [12].

A Kolmogorov-Smirnov test was performed to assess the normality of the variables. Body weight, age, time to endotracheal extubation, duration of surgery and recovery time were compared between groups using the Student's $t$-test. The Mann-Whitney $U$ test was used to compare additional morphine requirement, pain and sedation scores between groups. The Friedman test was used to compare differences in pain and sedation scores over time within each group. All analyses were performed using GraphPad Instat5. Differences were considered significant when $P<0.05$.

There were no significant differences between groups for demographic data. Mean \pm standard deviation of weight, age, time to endotracheal extubation, duration of surgery, recovery time and extent of mastectomy were: $13 \pm 10$ and $8 \pm$ $8 \mathrm{~kg} ; 8 \pm 3$ and $10 \pm 3$ years; $7 \pm 5$ and $6 \pm 2 \mathrm{~min} ; 87 \pm 20$ and $81 \pm 26 \mathrm{~min} ; 225 \pm 12$ and $213 \pm 15 \mathrm{~min}$ and $70.5 \pm 18$ and $68 \pm 15 \%$ (Gabapentin and Placebo groups, respectively). Histopathologic tumor classification was simple mammary carcinoma $(50 \%)$, complex mammary carcinoma $(37.5 \%)$ and amelanotic melanoma (12.5\%), with varying degrees of inflammation (slight to moderate).

The median pain scores (VAS and GCMPS) did not significantly differ between the treatment groups at any time point. The GCMPS pain scores were higher than the corresponding basal values at $2 \mathrm{hr}$ after extubation in both groups $(P<0.0001)$ (Table 1). Requirement for postoperative rescue analgesia was significantly lower in the Gabapentin than the Placebo group. In the first 24-hr period following surgery, 16 rescue doses of morphine were required for 8 dogs treated with the placebo, whereas only 9 rescue doses were needed for 6 dogs treated with gabapentin $(P=0.021)$ (Table 2). The degree of sedation was similar between the groups. However, compared with baseline values, higher scores were observed until 2 and $4 \mathrm{hr}$ after extubation in the Placebo and Gabapentin groups, respectively $(P<0.0001)$ (Table 1).

This study showed that the dogs in the Gabapentin group had a significantly lower incidence of rescue medication than the Placebo group, suggesting a superior level of analgesia when gabapentin was administered perioperatively. VAS and GCMPS pain scores did not differ significantly between groups at any time point. Any real differences between gabapentin and placebo treatments may have been attenuated by the administration of rescue analgesics. The perioperative oral administration of gabapentin reduced the requirement of rescue doses of morphine by $44 \%$ in the dogs. These results support the reports of a previous study where perioperative administration of gabapentin resulted in a 50\% reduction in the postoperative morphine consumption in women undergoing radical mastectomy [4].

With respect to pain assessment in animals, several scoring systems using a variety of scales (e.g., visual analog, numerical rating, simple descriptive and composite) have been developed and correlated specifically for dogs $[7,15,18]$. In the current study, two methods (i.e., the VAS and GCMPS) were used to obtain a more accurate overall impression of pain $[20,23]$. The VAS system is a simple method of scoring pain and is commonly used for both humans and animals. The GCMPS system is internationally recognized and is reported to be as reliable and reproducible as the VAS system for assessing pain in dogs [18]. In addition, in the present study, only one observer scored all the dogs to avoid interobserver variability in the subjective evaluation. Furthermore, a blinded assessor performed the pain assessment. We believed that the postoperative pain was evaluated objectively with minimum variability in the present study.

It has been suggested that central neuronal sensitization may play an important role not only in chronic pain states, such as neuropathic pain, but also in postoperative pain [17]. Although the precise mechanism by which gabapentin produces analgesia is unknown, the compound has a 
Table 1. Pain and sedation scores (median and lower-upper range) measured prior to surgery (ie, baseline) and at 0.5 , $1,2,4,6,8,12,18,24,32,40,48,56,64$ and $72 \mathrm{hr}$ after tracheal extubation in dogs undergoing mastectomy treated with gabapentin (Gabapentin) or placebo (Placebo)

\begin{tabular}{|c|c|c|c|c|c|c|}
\hline \multirow[b]{2}{*}{ Time } & \multicolumn{2}{|c|}{ VAS } & \multicolumn{2}{|c|}{ GMCPS } & \multicolumn{2}{|c|}{ Sedation scores } \\
\hline & Gabapentin & Placebo & Gabapentin & Placebo & Gabapentin & Placebo \\
\hline Baseline & $0(0-0)$ & $0(0-0)$ & $0.08(0.08-0.08)$ & $0.08(0.08-0.87)$ & $0(0-0)$ & $0(0-0)$ \\
\hline $0.5 \mathrm{hr}$ & $0(0-20)$ & $0(0-30)$ & $2.43(0.08-3.81)$ & $2.43(0.08-5.56)$ & $3(0-4)^{a)}$ & $3(1-4)^{a}$ \\
\hline $1 \mathrm{hr}$ & $0(0-10)$ & $5(0-50)$ & $2.43(0.08-3.55)$ & $1.99(0.08-3.81)$ & $3(0-4)^{a)}$ & $2.5(0-4)^{\mathrm{a})}$ \\
\hline $2 \mathrm{hr}$ & $0(0-30)$ & $20(0-30)$ & $2.43(0.87-3.55)^{\mathrm{a})}$ & $2.53(0.87-3.55)^{\mathrm{a})}$ & $1(0-3)^{\mathrm{a})}$ & $1.5(0-4)^{\mathrm{a})}$ \\
\hline $4 \mathrm{hr}$ & $5(0-30)$ & $20(0-60)$ & $1.89(0.08-3.37)$ & $3.08(0.08-4.55)$ & $1(0-3)^{a)}$ & $0(0-1)$ \\
\hline $8 \mathrm{hr}$ & $10(0-50)$ & $10(0-30)$ & $1.04(0.08-5.85)$ & $1.35(0.08-3.66)$ & $0(0-1)$ & $0(0-0)$ \\
\hline $12 \mathrm{hr}$ & $10(0-50)$ & $5(0-30)$ & $1.43(0.08-4.05)$ & $0.6(0.08-3.58)$ & $0(0-0)$ & $0(0-0)$ \\
\hline $18 \mathrm{hr}$ & $5(0-30)$ & $0(0-30)$ & $0.6(0.08-3.56)$ & $0.08(0.08-3.83)$ & $0(0-0)$ & $0(0-0)$ \\
\hline $24 \mathrm{hr}$ & $0(0-30)$ & $0(0-80)$ & $0.49(0.08-3.81)$ & $0.08(0.08-4.99)$ & $0(0-0)$ & $0(0-0)$ \\
\hline $32 \mathrm{hr}$ & $0(0-10)$ & $0(0-20)$ & $0.08(0.08-1.46)$ & $0.08(0.08-2.64)$ & $0(0-0)$ & $0(0-0)$ \\
\hline $40 \mathrm{hr}$ & $0(0-10)$ & $0(0-20)$ & $0.08(0.08-1.20)$ & $0.08(0.08-1.83)$ & $0(0-0)$ & $0(0-0)$ \\
\hline $48 \mathrm{hr}$ & $0(0-10)$ & $0(0-10)$ & $0.08(0.08-1.21)$ & $0.08(0.08-0.08)$ & $0(0-0)$ & $0(0-0)$ \\
\hline $56 \mathrm{hr}$ & $0(0-20)$ & $0(0-30)$ & $0.08(0.08-1.46)$ & $0.08(0.08-2.43)$ & $0(0-0)$ & $0(0-0)$ \\
\hline $64 \mathrm{hr}$ & $0(0-20)$ & $0(0-10)$ & $0.08(0.08-1.20)$ & $0.08(0.08-2.43)$ & $0(0-0)$ & $0(0-0)$ \\
\hline $72 \mathrm{hr}$ & $0(0-20)$ & $0(0-10)$ & $0.08(0.08-1.20)$ & $0.08(0.08-2.33)$ & $0(0-0)$ & $0(0-0)$ \\
\hline
\end{tabular}

a) Differences from baseline in each group (Friedman test, $P<0.05)$. VAS=Visual Analogue scale $(0-100 \mathrm{~mm})$; GMCPS= Glasgow Modified Composite Pain Score (0-10).

Table 2. Number of morphine doses administered to each dog, and total number of morphine doses administered to each treatment group over time in dogs undergoing mastectomy treated with gabapentin (Gabapentin) or placebo (Placebo)

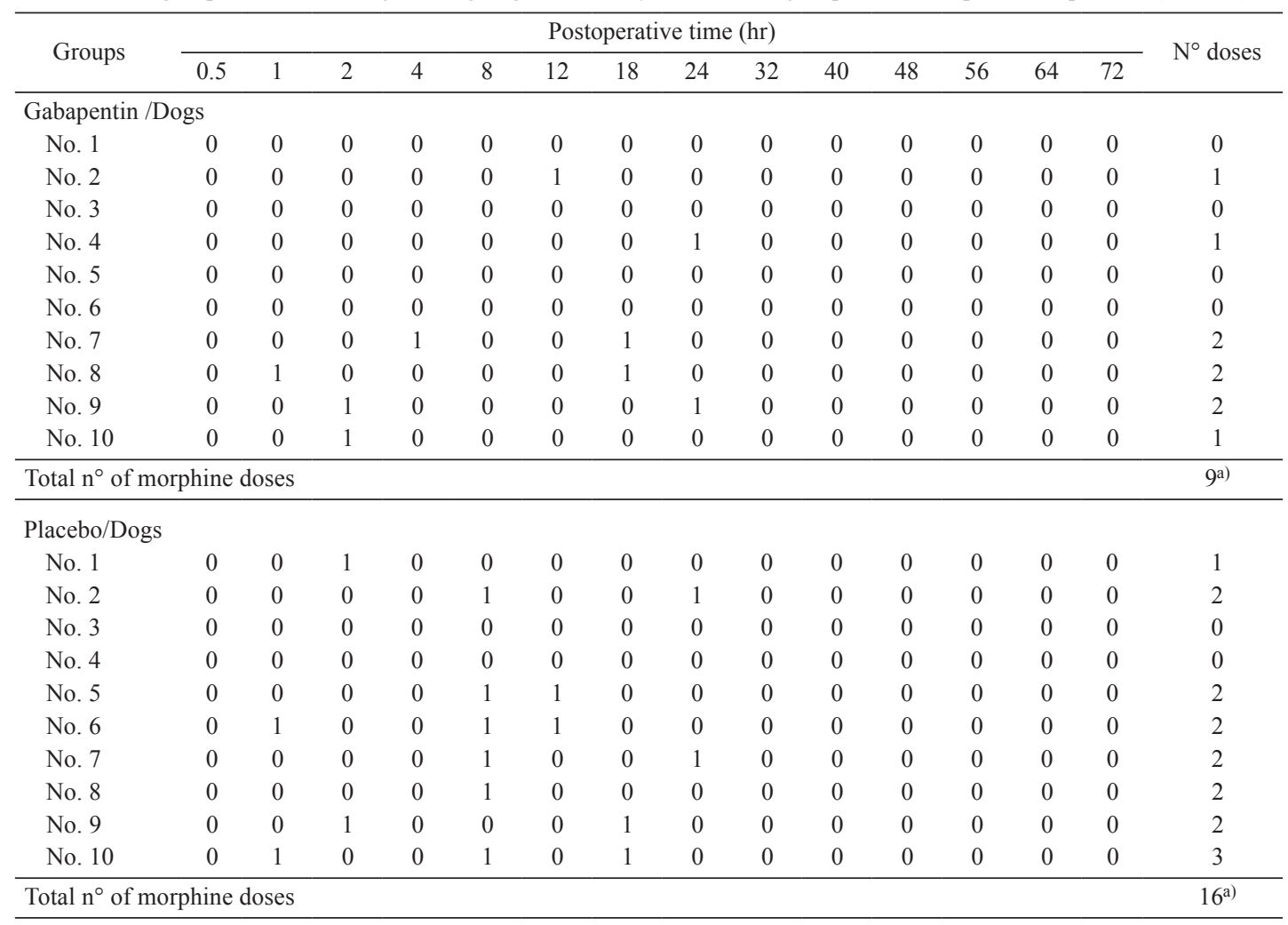

a) Significant difference between groups (Mann-Whitney $U$ test, $P=0.021$ ).

high binding affinity for the $\alpha_{2} \delta$ subunit of the presynaptic voltage-gated calcium channels, which inhibits calcium influx and subsequent release of excitatory neurotransmit- ters including glutamate, substance $\mathrm{P}$ and noradrenaline $[11,22]$. These channels are upregulated in the dorsal root ganglia and spinal cord after surgical trauma [9]. In animal 
models, gabapentin has been shown to prevent allodynia and hyperalgesia $[8,11]$. Other theories regarding the analgesic effects of gabapentin relate to its inhibitory effect on dorsal horn N-methyl-D-aspartic acid receptors [13]. Postoperative pain following mastectomy may induce an inflammatory response that leads to hyperalgesia of the surgical incision with sensitization of peripheral nociceptive nerve terminals and central neurons [14]. For this reason, all dogs were given meloxicam before and postsurgery. When used to control postoperative pain, both nonsteroidal anti-inflammatory drugs (NSAIDs) and gabapentin have been shown to have a significant opioid-sparing efficacy [3, 4, 23]. NSAIDs (i.e., meloxicam) inhibit peripheral and central nervous system prostaglandin synthesis [16], and gabapentin reduces the hyperexcitability of dorsal horn neurons following tissue damage [9]. Clinical trials in humans suggest that the use of the combination of these two non-opioid analgesics promotes superior reduction in opioid requirements $[5,17]$. The present study supports these findings and demonstrates that as part of a multimodal analgesic regimen, gabapentin provides a significant effect on analgesic requirements after mastectomy in dogs. Thus, antihyperalgesic drugs, such as gabapentin, may have a role in postoperative pain, and the combination with other antinociceptive drugs may prevent or reduce the peripheral and central sensibilization induced by the surgical procedure, resulting in a decreased need for additional postoperative pain treatment.

Unfortunately, there is insufficient information to recommend a specific dose regimen for gabapentin in dogs. In humans, the analgesic efficacy of gabapentin has been associated with $2-3 \mu \mathrm{g} / \mathrm{m} l$ plasma concentrations [25]. Using dogs, Kukanich and Koen [10] studied the pharmacokinetic properties of oral gabapentin at $10-20 \mathrm{mg} / \mathrm{kg}$. The results of this trial showed that plasma concentrations of gabapentin exceeded $2 \mu \mathrm{g} / \mathrm{m} l$ in the majority of dogs only until 8 $\mathrm{hr}$, suggesting that gabapentin was rapidly absorbed and eliminated, and frequent dosing is needed to maintain the minimum targeted plasma concentrations. The dose used in the current study was based on textbook recommendations and recent trials in dogs $[1,26]$. Our results showed that 10 $\mathrm{mg} / \mathrm{kg}$ twice a day of gabapentin did not decrease the pain levels when compared with the placebo treatment, which may be associated with an insufficient dose for postoperative pain control in dogs. Using the same dosing regimen in dogs undergoing hemilaminectomy, Aghighi et al. [1] did not find a detectable reduction in pain scores compared to opioid analgesia alone. This study also reported that in $21.5 \%$ and $23.1 \%$ of the gabapentin treated dogs, serum concentrations fell below $3 \mu \mathrm{g} / \mathrm{ml}$ at $24 \mathrm{hr}$ and $72 \mathrm{hr}$, respectively, suggesting that the dose and dose interval were too low to obtain stable serum concentrations.

The design of this study has some limitations. The variability inherent in this type of a clinical study may have contributed to the lack of significant differences in postoperative pain; it was difficult to control the degree of surgical trauma. The randomization of dogs between treatments resulted in groups that were not completely homogeneous. There was a difference with respect to the type of neoplasia and extent of mastectomy, which may also have affected the intensity of postoperative pain. This variability may have confounded the pain scoring in the present study. Moreover, the number of dogs was also limited, because of the inclusion criteria and need for owner consent.

In humans, the major side effects reported from the use of gabapentin include sedation, dizziness and nausea [9]. Although there were no statistical differences in sedation scores between groups, compared with the baseline values, greater sedation scores were observed at $2 \mathrm{hr}$ and $4 \mathrm{hr}$ after extubation in the Placebo and Gabapentin groups, respectively. These findings suggest that gabapentin prolonged the sedation effect, and this result is in agreement with previous studies $[3,6]$. Nausea and vomiting were observed in the majority of dogs after the premedication, but this effect is associated with morphine [19]. Thus, it appears that gabapentin did not induce relevant adverse effects.

In conclusion, at the dose and frequency used in this study, perioperative gabapentin reduced the requirement of postoperative rescue analgesia in dogs after mastectomy.

ACKNOWLEDGMENT. Supported by the 'Fundação de Amparo à Pesquisa de São Paulo’ (grant number 2012/11988-4).

\section{REFERENCES}

1. Aghighi, S. A., Tipold, A., Piechotta, M., Lewczuk, P. and Kästner, S. B. 2012. Assessment of the effects of adjunctive gabapentin on postoperative pain after intervertebral disc surgery in dogs. Vet. Anaesth. Analg. 39: 636-646. [Medline] [CrossRef]

2. Cashmore, R. G., Harcourt-Brown, T. R., Freeman, P. M., Jeffery, N. D. and Granger, N. 2009. Clinical diagnosis and treatment of suspected neuropathic pain in three dogs. Aust. Vet. J. 87: 45-50. [Medline] [CrossRef]

3. Clarke, H., Pereira, S., Kennedy, D., Gilron, I., Katz, J., Gollish, J. and Kay, J. 2009. Gabapentin decreases morphine consumption and improves functional recovery following total knee arthroplasty. Pain Res. Manag. 14: 217-222. [Medline]

4. Dirks, J., Fredensborg, B. B., Christensen, D., Fomsgaard, J. S., Flyger, H. and Dahl, J. B. 2002. A randomized study of the effects of single-dose gabapentin versus placebo on postoperative pain and morphine consumption after mastectomy. Anesthesiology 97: 560-564. [Medline] [CrossRef]

5. Gilron, I., Orr, E., Tu, D., O’Neill, J. P., Zamora, J. E. and Bell, A. C. 2005. A placebo-controlled randomized clinical trial of perioperative administration of gabapentin, rofecoxib and their combination for spontaneous and movement-evoked pain after abdominal hysterectomy. Pain 113: 191-200. [Medline] [CrossRef]

6. Grover, V. K., Mathew, P. J., Yaddanapudi, S. and Sehgal, S. 2009. A single dose of preoperative gabapentin for pain reduction and requirement of morphine after total mastectomy and axillary dissection: randomized placebo-controlled double-blind trial. J. Postgrad. Med. 55: 257-260. [Medline] [CrossRef]

7. Holton, L., Reid, J., Scott, E. M., Pawson, P. and Nolan, A. 2001. Development of a behaviour-based scale to measure acute pain in dogs. Vet. Rec. 148: 525-531. [Medline] [CrossRef]

8. Hurley, R. W., Chatterjea, D., Rose Feng, M., Taylor, C. P. and Hammond, D. L. 2002. Gabapentin and pregabalin can interact synergistically with naproxen to produce antihyperalgesia. Anesthesiology 97: 1263-1273. [Medline] [CrossRef]

9. Kong, V. K. and Irwin, M. G. 2007. Gabapentin: a multimodal 
perioperative drug? Br. J. Anaesth. 99: 775-786. [Medline] [CrossRef]

10. Kukanich, B. and Cohen, R. L. 2011. Pharmacokinetics of oral gabapentin in greyhound dogs. Vet. J. 187: 133-135. [Medline] [CrossRef]

11. Luo, Z. D., Calcutt, N. A., Higuera, E. S., Valder, C. R., Song, Y. H., Svensson, C. I. and Myers, R. R. 2002. Injury type-specific calcium channel alpha 2 delta- 1 subunit up-regulation in rat neuropathic pain models correlates with antiallodynic effects of gabapentin. J. Pharmacol. Exp. Ther. 303: 1199-1205. [Medline] [CrossRef]

12. MacDougall, L. M., Hethey, J. A., Livingston, A., Clark, C., Shmon, C. L. and Duke-Novakovski, T. 2009. Antinociceptive, cardiopulmonary, and sedative effects of five intravenous infusion rates of lidocaine in conscious dogs. Vet. Anaesth. Analg. 36: 512-522. [Medline] [CrossRef]

13. Maneuf, Y. P., Gonzalez, M. I., Sutton, K. S., Chung, F. Z., Pinnock, R. D. and Lee, K. 2003. Cellular and molecular action of the putative GABA-mimetic, gabapentin. Cell. Mol. Life Sci. 60: 742-750. [Medline] [CrossRef]

14. Minto, B. W., Rodrigues, L. C., Steagall, P. V., Monteiro, E. R. and Brandão, C. V. 2013. Assessment of postoperative pain after unilateral mastectomy using two different surgical techniques in dogs. Acta Vet. Scand. 55: 60-65. [Medline] [CrossRef]

15. Murrell, J. C., Psatha, E. P., Scott, E. M., Reid, J. and Hellebrekers, L. J. 2008. Application of a modified form of the Glasgow pain scale in a veterinary teaching centre in the Netherlands. Vet. Rec. 162: 403-408. [Medline] [CrossRef]

16. Ochroch, E. A., Mardini, I. A. and Gottschalk, A. 2003. What is the role of NSAIDs in pre-emptive analgesia? Drugs 63: 2709-2723. [Medline] [CrossRef]

17. Parsa, A. A., Sprouse-Blum, A. S., Jackowe, D. J., Lee, M., Oyama, J. and Parsa, F. D. 2009. Combined preoperative use of celecoxib and gabapentin in the management of postoperative pain. Aesthetic Plast. Surg. 33: 98-103. [Medline] [CrossRe]

18. Rialland, P., Authier, S., Guillot, M., Del Castillo, J. R., Veilleux-Lemieux, D., Frank, D., Gauvin, D. and Troncy, E. 2012.
Validation of orthopedic postoperative pain assessment methods for dogs: a prospective, blinded, randomized, placebo-controlled study. PLoS ONE 7: e49480. [Medline] [CrossRef]

19. Sarrau, S., Jourdan, J., Dupuis-Soyris, F. and Verwaerde, P. 2007. Effects of postoperative ketamine infusion on pain control and feeding behaviour in bitches undergoing mastectomy. J. Small Anim. Pract. 48: 670-676. [Medline] [CrossRef]

20. Shih, A. C., Robertson, S., Isaza, N., Pablo, L. and Davies, W. 2008. Comparison between analgesic effects of buprenorphine, carprofen, and buprenorphine with carprofen for canine ovariohysterectomy. Vet. Anaesth. Analg. 35: 69-79. [Medline]

21. Sleeckx, N., de Rooster, H., Veldhuis Kroeze, E. J. B., Van Ginneken, C. and Van Brantegem, L. 2011. Canine mammary tumours, an overview. Reprod. Domest. Anim. 46: 1112-1131. [Medline] [CrossRef]

22. Taylor, C. P., Gee, N. S., Su, T. Z., Kocsis, J. D., Welty, D. F., Brown, J. P., Dooley, D. J., Boden, P. and Singh, L. 1998. A summary of mechanistic hypotheses of gabapentin pharmacology. Epilepsy Res. 29: 233-249. [Medline] [CrossRef]

23. Teixeira, R. C., Monteiro, E. R., Campagnol, D., Coelho, K., Bressan, T. F. and Monteiro, B. S. 2013. Effects of tramadol alone, in combination with meloxicam or dipyrone, on postoperative pain and the analgesic requirement in dogs undergoing unilateral mastectomy with or without ovariohysterectomy. Vet. Anaesth. Analg. 40: 641-649. [Medline] [CrossRef]

24. Vettorato, E. and Corletto, F. 2011. Gabapentin as part of multimodal analgesia in two cats suffering multiple injuries. Vet. Anaesth. Analg. 38: 518-520. [Medline] [CrossRef]

25. Vollmer, K. O., von Hodenberg, A. and Kölle, E. U. 1986. Pharmacokinetics and metabolism of gabapentin in rat, dog and man. Arzneimittelforschung 36: 830-839. [Medline]

26. Wagner, A. E., Mich, P. M., Uhrig, S. R. and Hellyer, P. W. 2010. Clinical evaluation of perioperative administration of gabapentin as an adjunct for postoperative analgesia in dogs undergoing amputation of a forelimb. J. Am. Vet. Med. Assoc. 236: 751-756. [Medline] [CrossRef] 